\title{
A IMPORTÂNCIA DA AFETIVIDADE NA EDUCAÇÃo
}

\author{
LA IMPORTANCIA DE LA AFETIVIDAD EN LA EDUCACIÓN
}

THE IMPORTANCE OF EDUCATIONAL AFFECTIVENESS

\author{
Gabriella Rossetti FERREIRA ${ }^{1}$ \\ Paulo Rennes Marçal RIBEIRO ${ }^{2}$
}

RESUMO: A afetividade é um estado psicológico humano, logo faz parte da escolarização e do processo de ensino-aprendizagem. O objetivo deste artigo é demonstrar como e porque a afetividade está vinculada ao processo de ensino-aprendizagem, ressaltando que, sem o estabelecimento de vínculos afetivos, não é possível o aprendente disponibilizar energia para que seu desejo de aprender se manifeste. Desta forma, é possível afirmar que não haverá aprendizagem se não houver o desenvolvimento cognitivo e afetivo, concomitantemente. A afetividade tem sido alvo de estudo de muitos autores, e todos são unânimes em afirmarem que o desenvolvimento humano integral deve ter cognição afeição. Não raro, encontramos crianças que não aprendem ou, que não desejam aprender, uma vez que são incapazes de estabelecer vínculos afetivos com a escola e com os professores. A escola é o primeiro ambiente de vivência longe dos pais e da família, por isso deve ser acolhedor e passível aos desenvolvimento afetivo.

PALAVRAS-CHAVE: Aprendizagem. Afetividade. Vínculo. Escola.

RESUMEN: La afectividad es un estado psicológico humano, luego forma parte de la escolarización y del proceso de enseñanza-aprendizaje. El objetivo de este artículo es demostrar cómo y por qué la afectividad está vinculada al proceso de enseñanza-aprendizaje, resaltando que, sin el establecimiento de vínculos afectivos, no es posible que el alumno disponga energía para que su deseo de aprender se manifieste. De esta forma, es posible afirmar que no habrá aprendizaje si no existe el desarrollo cognitivo y afectivo, concomitantemente. La afectividad ha sido objeto de estudio de muchos autores, y todos son unánimes en afirmar que el desarrollo humano integral debe tener cognición afección. No es raro encontrar niños que no aprenden o que no desean aprender, ya que no pueden establecer vínculos afectivos con la escuela y los profesores. La escuela es el primer ambiente de vivencia lejos de los padres y de la familia, por lo que debe ser acogedora y pasible al desarrollo afectivo.

PALABRAS CLAVE: Aprendizaje. La afectividad. Bond. Escuela.

1 Universidade Estadual Paulista (UNESP), Araraquara - SP - Brasil. Doutoranda de Pós-Graduação em Educação Escolar. ORCID: http://orcid.org/0000-0003-4682-8914. E-mail: gaby_gabriella13@ @otmail.com ${ }^{2}$ Universidade Estadual Paulista (UNESP), Araraquara - SP - Brasil. Professor do Departamento de Psicologia da Educação e Coordenador do Programa de Pós-Graduação em Educação Sexual. ORCID: https://orcid.org/0000-0002-1552-5702. E-mail: paulo.rennes@unesp.br e-ISSN: 2594-8385. 
ABSTRACT: Affectivity is a human psychological state, so it is part of schooling and the teaching-learning process. The aim of this article is to demonstrate how and why affectivity is linked to the teaching-learning process, emphasizing that without the establishment of affective bonds, it is not possible for the learner to provide energy so that his desire to learn is manifested. In this way, it is possible to affirm that there will be no learning if there is no cognitive and affective development, concomitantly. The affectivity has been the subject of study by many authors, and all are unanimous in stating that integral human development must have cognition affection. Not infrequently, we find children who do not learn or who do not wish to learn since they are unable to establish affective bonds with the school and with teachers. The school is the first living environment away from parents and family, so it should be welcoming and amenable to affective development.

KEYWORDS: Learning. Affectivity. Bond. School.

\section{Introdução}

Durante muitos anos a escola era apenas um local onde se aprendia conteúdos os conhecimentos pré-estabelecidos e onde o professor era o centro do conhecimento. Entretanto, o movimento Escola Nova, introduzido por John Dewey (1849-1923), entendia que a educação era uma necessidade social, e, em função dessa necessidade, as pessoas deveriam aperfeiçoar-se, no sentido de renovação, de forma a dar prosseguimento a esta necessidade de mudança, uma vez que, a vida nunca é estática e está em constante transformação.

A mais notável distinção entre os seres vivos e inanimados é que os primeiros se conservam pela renovação. Ao receber uma pancada, a pedra opõe resistência. Se a resistência for maior do que a força da pancada, ela, exteriormente, não apresentará mudança; no caso contrário se partirá em fragmentos menores que ela. (DEWEY, 1959, p. 1).

A Educação, para Dewey (1959, p. 8):

É um processo de reconstrução e reorganização de experiências, pelo qual lhe percebemos mais agudamente o sentido e com isso nos habilitamos a melhor dirigir o curso de nossas experiências futuras.

Para o escolanovismo, a educação, é fundamental para a construção de uma sociedade democrática, que respeita o individualismo dos sujeitos aprendentes, as diversidades, e tornam as pessoas capazes de refletir sobre a sociedade e tornarem-se capazes de nela estar inseridos. Dessa forma, a escolarização deve centrar sua atenção no indivíduo de forma que o prepare para a vida. Como dizia Anísio Teixeira (2000, p. 16): 
O próprio ato de aprender, durante muito tempo significou simples memorização; depois seu sentido passou a incluir a compreensão e a expressão do que fora ensinado; por último, envolveu algo mais: ganhar um modo de agir. Só aprendemos quando assimilamos uma coisa de tal jeito que, chegado o momento oportuno, sabemos agir de acordo com o aprendido.

Dessa forma, tal movimento foi percursor de uma nova visão para a educação no Brasil, deixando para a escola não apenas a função de ensinar, mas também de inserir os alunos de forma integral na sociedade. $\mathrm{O}$ desenvolvimento cognitivo, não deveria mais ser levado em consideração apenas como um fator isolado, mas sim, como um dos fatores que promovem o desenvolvimento do indivíduo, mas não o único.

Como explica Dewwy (1959, p. 86), a Educação tem como eixo norteador a vidaexperiência e aprendizagem, fazendo com que sua função seja a de propiciar uma reconstrução permanente da experiência e da aprendizagem dentro de sua vida.

Com esta nova visão, a escola não deveria apenas ensinar, sendo responsável também por educar, preparar para o futuro, dar ferramentas para as pessoas serem livres e não apenas instruídas, sem fazer questionamentos e argumentações críticas. A escola deveria assumir a sua responsabilidade de ensinar a viver com mais inteligência, tolerância e responsabilidade.

Não se aprendem apenas ideias ou fatos, mas também atitudes, ideais e senso crítico - desde que a escola disponha de condições para exercitá-los. Assim, uma criança só pode praticar a bondade em uma escola onde haja condições reais para desenvolver o sentimento. A nova psicologia da aprendizagem obriga a escola a se transformar num local onde se vive e não em um centro preparatório para a vida. Como não aprendemos tudo o que praticamos, e sim aquilo que nos dá satisfação, o interesse do aluno deve orientar o que ele vai aprender. Portanto, é preciso que ele escolha suas atividades. (CELSO MILAN, 2011, p. 45).

No início do século XX, muitos autores já pesquisavam sobre como se dá o desenvolvimento integral das crianças, trazendo à luz discussão de quais fatores são importantes para o desenvolvimento integral do sujeito, e a afetividade surgiu como fator indissociável do cognitivo. A partir daí, deu-se início a várias teorias do processo ensinoaprendizagem, todos considerando que o cognitivo e o afetivo devem estar sempre em desenvolvimento contínuo e concomitante.

A aprendizagem não é um ato isolado nem neutro afetivamente, só pode ser concebida num contexto de transmissão intencional e de, atenção e interação emocional compartilhada, o que por si só integra emoções e cognições, leitura de faces e de mentes, exibição de sinais não 
verbais e corporais de tristeza, alegria, desgosto, surpresa, zanga, medo, etc (FONSECA, 2016, 2000; ROURKE, 1989)

Teorias sobre a afetividade como fator essencial para o bom desempenho escolar foram surgindo, os autores Piaget, Vygotsky, Wallon, Antônio Damásio, entre outros deram contribuições imprescindíveis para área.

Piaget, Vygotsky e Wallon, ao implementarem investigações acerca do desenvolvimento psicológico humano acabam por identificar na afetividade o seu caráter social, amplamente dinâmico e construtor da personalidade humana, além de estabelecer o elo de ligação entre o indivíduo e a busca do saber (por meio das interações sociais), tendendo os três autores, para o postulado de que, embora considerada sob diversas matrizes, à afetividade cabe a função desencadeadora do agir e do pensar humano, isto é, para a efetivação do desenvolvimento sócio cognitivo. (COSTA; SOUZA, 2012, p. $12)$.

A partir do estudo de como se dá a aquisição de conhecimento nos sujeitos, desde as percepções sensoriais, perpassando por todos os aspectos do desenvolvimento infantil, psicomotricidade e sociabilidade, é possível notar que o desejo de aprender está intrinsecamente relacionado aos aspectos afetivos vivenciados pelos alunos.

As formas de ensinar que levam em consideração a afetividade, não só facilitam o processo de ensino-aprendizagem, como também, na maioria das vezes, ajuda àquelas crianças que por algum motivo, seja patológico, endógeno ou exógeno, estão com suas capacidades de aprender bloqueadas.

\section{Algumas teorias sobre afetividade}

Henry Wallon (1879-1962), Jean Piaget (1896-1980) e Lev Vygotsky (1896-1934), são alguns dos autores que estudaram o desenvolvimento da criança, a construção do conhecimento e inteligência, e que, ao mesmo tempo, propuseram teorias sobre a importância da afetividade. Embora com abordagens diferentes, criaram conceitos que auxiliam a entender a importância da afetividade.

Vygotsky, dentre seus vários textos relacionados à afetividade, escreveu A Educação do Comportamento Emocional (2003), nesta obra esboça que sua preocupação estava no fato da afetividade e cognição encontrarem-se fragmentas, pois, para ele, as dimensões cognitivas e afetivas estão no desenvolvimento da criança desde cedo, sendo as várias experiências 
vividas e a interação com as outras pessoas representam fatores imprescindíveis para a compreensão dos processos envolvidos na construção do conhecimento.

Como aponta Vygotsky (1996, p. 39):

\begin{abstract}
A forma de pensar, que junto com o sistema de conceito nos foi imposta pelo meio que nos rodeia, inclui também nossos sentimentos. Não sentimos simplesmente: o sentimento é percebido por nós sob a forma de ciúme, cólera, ultraje, ofensa. Se dizemos que desprezamos alguém, o fato de nomear os sentimentos faz com que estes variem, já que mantêm uma certa relação com nossos pensamentos.
\end{abstract}

Deste modo, as emoções tidas como integrantes das funções mentais superiores, são antes, produto da inserção humana num dado contexto sócio histórico. O pensamento tem sua origem no campo da motivação, a qual abrange inclinações, necessidades, interesses, impulsos, afeto e emoção.

Este autor buscou no desenvolvimento da linguagem, os elementos fundamentais para a integração das emoções com o funcionamento mental geral, uma vez que, considera a linguagem como sistema simbólico.

Em Vygotsky, a linguagem configura-se como um lugar de constituição e expressão dos modos de vida culturalmente elaborados, fornecendo os conceitos e as formas de organização do real.

a manifestação inicial da emoção parte da herança biológica, mas, junto com outras funções psicológicas, nas interações sociais, ela perde seu caráter instintivo para dar lugar a um nível mais complexo de atuação do ser humano, consciente e autodeterminado. [...] a atividade humana é explicada com referência a influências sociais e culturais e pela reconstituição de seu desenvolvimento histórico na filogenia e na ontogenia (VAN DER VEER; VALSINER, 1996, p. 386).

Vygotsky demonstrava que a criança incorpora instrumentos culturais através da linguagem e que, portanto, os processos psicológicos afetivos e cognitivos da criança são determinados, em última instância, por seu ambiente cultural e social. Segundo ele, o aprendizado humano pressupõe uma natureza social específica e um processo através no qual as crianças penetram na vida intelectual dos que a cercam” (VIGOTSKY, 1984, p. 99).

Outro autor que busca a mostrar a importância da afetividade no desenvolvimento humano é Henry Wallon. Ele defende a ideia de que a interação social é um fator importante para a construção do ser humano, salientando que o desenvolvimento sensório e motor, são influenciados pela qualidade dos afetos vivenciados pelas crianças. 
Jamais pude dissociar o biológico e o social, não porque o creia redutíveis entre si, mas porque, eles me parecem tão estreitamente complementares, desde o nascimento, que a vida psíquica só pode ser encarada tendo em vista suas relações recíprocas (WEREBE; NADEL-BRULFRT, 1986, p. 8).

Na concepção walloniana, a dimensão afetiva é um ponto extremamente importante na teoria psicogenética, ocupa lugar central, tanto do ponto de vista da construção da pessoa, quando do conhecimento.

a afetividade e a inteligência constituem um par inseparável na evolução psíquica, pois ambas têm funções bem definidas e, quando integradas, permitem à criança atingir níveis de evolução cada vez mais elevados. (WALLON, 1999, p. 51).

Wallon explica que o estado afetivo pode resultar em dificuldades de aprendizagem ou pode resultar em facilidade de aprendizagem, tendo como resultado o sucesso ou o fracasso escolar, comprometendo assim, o estado afetivo. Para ele, as emoções e sentimentos negativos, ou seja, a falta deles ou a forma indiferente de demonstração de afeto, podem contaminar o ambiente escolar. Um ambiente afetivo é aquele que promove sentimentos de alegria, de bem-estar, de acolhimento e, efetivamente auxiliam nos resultados em sala de aula.

Segundo Wallon (apud ALMEIDA, 1997, p. 51), é a emoção que estabelece a ligação entre a vida orgânica e a vida psíquica.

A afetividade é fundamental no desenvolvimento da personalidade, nascendo, inclusive, antes da inteligência. A princípio, a afetividade é apenas expressão motora ("diálogo tônico", ou seja, a criança se comunica através de movimentos, resultantes de manifestações de alegria e prazer diante do toque do adulto) e com o tempo a criança vai incorporando a linguagem e esta se torna cada vez mais forte na criança, que cada vez mais vai querer ouvir e ser ouvida. "O elogio transmitido por palavras substitui o carinho" (ALMEIDA, 1997, p. 51).

Henry Wallon (1971) enfatizou em seus trabalhos que todo o contato que a criança estabelece com as pessoas que cuidam dela, desde o nascimento, são feitos de emoções e não apenas de cognição. Sendo a afetividade, considerada um instrumento de sobrevivência.

Wallon (1971) também apresenta a importância da movimentação no desenvolvimento das crianças, uma vez que são indicadores dos estados emocionais, pois representam as emoções. 
os movimentos como expressões de natureza afetiva, podem gerar emoções e ser resultado delas [...] a alegria, ao se produzir na criança, desencadeia uma grande excitação motora; a criança, ao ficar dividida entre o movimento de realização da atividade e os movimentos de entusiasmo, geralmente entregase a este último. Os professores devem ficar atentos aos movimentos das crianças, pois estes podem ser indicadores de estados emocionais que devem ser levados em conta no contexto de sala de aula. (ALMEIDA, 1999, p. 90)

Portanto, a criança passa a usar os movimentos para interação com o meio físico, e é a partir daí, que o movimento ganha caráter cognitivo. Os gestos e movimentos são os primeiros indícios da vida psíquica.

Vale destacar que a educação e pedagogia em Wallon são consideradas um fato social, uma vez que o homem é um ser social e membro de uma dada sociedade, e na realidade concreta que ele vive, atua e procura modifica-la.

Já Piaget (1964), enfatiza que a afetividade tem um papel regulador, principalmente para o desenvolvimento da inteligência sensório-motora, que ocorre entre os 6 e os 8 meses de idade e da fala, aos 2 anos. Ele explica que, ao brincar, a criança utiliza suas estruturas cognitivas e coloca em prática ações que estimulam sua aquisição de conhecimentos.

Ao utilizar-se da ludicidade, oportuniza-se as crianças o desenvolver da imaginação, criatividade, emoções e humor através de momentos de interação e socialização com o brincar, com jogos e brincadeiras dirigidas onde o criar e recriar sejam o foco principal das atividades desenvolvidas no ambiente educacional.

O desenvolvimento cognitivo, afetivo e social encontram-se tão imbricados um ao outro, a ponto de uma simples mudança circunstancial em um desses aspectos ocasionar a transformação dos demais, positiva ou negativamente, dependendo da situação. Enfim, "esses dois aspectos são ao mesmo tempo, irredutíveis, indissociáveis e complementares". (PIAGET apud INHELDER, 1990, p. 24).

Para ele, toda a conduta possui um aspecto afetivo (energético) e estrutural (orgânico) e que ambos devem ser estudados e levados em conta no desenvolvimento infantil.

Para que inteligência funcione, é preciso um motor que é o afetivo. Jamais se procurará resolver um problema se ele não lhe interessa. O interesse, a motivação afetiva é o móvel de tudo. (BRINGUIER, 1977, p. 71-72).

Ele defende a ideia de que não existem estados afetivos sem elementos cognitivos, assim como, não existem comportamentos puramente cognitivos. Considera os sentimentos, como um motor que impulsiona a ação. A afetividade é atribuída como uma condição inevitável na construção da inteligência, mas também, não é suficiente. Sem afeto não haveria 
interesse, nem necessidade, nem motivação, e consequentemente, perguntas ou problemas nunca seriam formulados e não haveria inteligência.

Discorre Piaget (1996), que nenhum conhecimento, mesmo que puramente perceptivo, não é uma simples cópia do real ou se encontra totalmente determinado pela mente do indivíduo. É produto de uma interação entre o sujeito e o objeto. É a interação provocada pelas atitudes espontâneas do organismo e pelos estímulos externos. E esse conhecimento é, portanto, aprendizagem, fruto de uma relação que nunca tem um sentido só, e é o resultado dessa interação.

Percebe-se que os três autores, se referem à emoção e à afetividade, tanto como forma de expressão de sentimentos, quanto como fator inato do ser humano. Nos bebês, os sentimentos se traduzem, por exemplo, através dos movimentos ou atitudes, manifestam-se através do corpo, diante de alguma situação de conforto ou desconforto, da mesma forma, é possível compreender quando os alunos estão descontentes, ou eufóricos, diante do objeto do conhecimento que está sendo trabalhado (passividade, agressividade, impaciência, euforismo).

A afetividade do professor, no que tange à forma e o gosto com que disponibiliza o conteúdo, prepara sua aula, se preocupa com seus alunos, percebe as manifestações dos sentimentos deles, será notado pelos alunos, criando um vínculo de afeto. Desta forma, estará usando a afetividade, que é o que o move em direção a um desejo, é o que estabelece um vínculo com aquilo que desejamos.

Esta distinção é importante para que os professores possam identificar, através dos movimentos das crianças, o que elas estão tentando demonstrar, ao passo que a afetividade fará com que seja possível reconhecer os sentimentos e torná-los adequados às situações em sala de aula.

É por meio da afetividade que os professores se mostram aos alunos, pela sua disponibilidade de compreensão dos sentimentos expressados por eles, trazendo assim, de forma prazerosa e acolhedora, o objeto de aprendizagem, de forma a estabelecer um vínculo, entre o aluno e a aprendizagem, criando nele a energia necessária para que possa aprender.

Atualmente, novas pesquisas, como a Inteligência Emocional de Goleman, e as Inteligências múltiplas de Gardner, tem demonstrado que existem áreas específicas no cérebro que atuam diretamente em nossos sentimentos, comprovando, cientificamente, as teorias expostas no início do século XX. 
No Programa de Aprendizagem Emocional (SEL - social and emotional learning), implantado em algumas escolas norte-americanas (2011), o objetivo era ensinar habilidades de inteligência emocional em crianças. Conforme Goleman (2012, p. 110):

[...] nos primeiros anos do ensino fundamental, as atividades de empatia devem tornar a criança capaz de identificar as pistas não-verbais de como uma pessoa se sente; nos últimos ciclos do fundamental, elas devem ser capazes de analisar o que gera o estresse nelas ou o que as motiva ater desempenhos melhores. E no Ensino médio, as habilidades de SEL, incluem ouvir e falar de modo a solucionar conflitos em vez de agravá-los e negociar saídas que todos ganhem.

As conclusões de Goleman (2012, p. 11), sobre o impacto deste programa, demonstraram:

a) Grandes benefícios no desempenho acadêmico: mais de 50\% das crianças tiveram progresso nas pontuações de desempenho, mais de $38 \%$ aumentaram suas médias; b) As escolas tornaram-se mais seguras, ocorrências de mau comportamento caíram em $28 \%$, suspensões em $44 \%$ e outros atos disciplinares $27 \%$. c) Aumento do percentual de presença e $63 \%$ dos alunos demonstraram comportamento significativamente mais positivo.

Paralelamente, diz Goleman, (2012, p. 11), que boa parte da eficiência do SEL veio do seu impacto na modelagem do circuito neural em desenvolvimento na criança, principalmente as funções executivas do córtex pré-frontal, que controlam a memória funcional- o que guardamos na cabeça durante o aprendizado - e inibem impulsos emocionais destrutivos. E que, grande parte da melhora na aprendizagem pode ser atribuída ao aperfeiçoamento da atenção e da memória funcional, funções-chave do córtex pré-frontal. Isto sugere veementemente que a neuroplasticidade - a modelagem do cérebro através de experiências repetidas - exerce um papel crucial nos benefícios do SEL.

A partir do exposto nessas pesquisas, conclui-se que há, no cérebro, funções específicas que podem ser moldadas, através da plasticidade cerebral, com sua ativação repetida. Assim, a modulação das emoções e dos afetos estão intrinsecamente ligados ao nosso comportamento.

Vale enfatizar que, a postura da escola e dos professores com relação aos alunos é fator determinante para o bom desenvolvimento do aprendizado cognitivo, afetivo e social, corroborando com as teorias de Wallon, Piaget e Vygotsky. 


\title{
A importância da afetividade na educação escolar
}

\begin{abstract}
A educação afetiva deveria ser a primeira preocupação dos educadores, porque é um elemento que condiciona o comportamento, o caráter e a atividade cognitiva da criança. E o amor não é contrário ao conhecimento, podendo tornar-se lucidez, necessidade e alegria de aprender. Quando se ama o mundo, esse amor ilumina e ajuda a revelá-lo e a descobri-lo. (SNYDERS, 1998).
\end{abstract}

Considera-se aqui a emoção como componente biológico do comportamento humano (agitação de ordem física) e a afetividade como expressão daquilo que se relaciona às vivências dos sujeitos relacionadas às formas de expressão mais complexas. Tais fenômenos, tanto o afeto quanto a emoção, referem-se às experiências subjetivas de cada indivíduo e são afetados pelos acontecimentos e pelo sentido que tais acontecimentos têm na vida de cada um, e como se refletem no íntimo de cada sujeito.

Wallon (1975, p. 43) em seus estudos, diferencia emoção e afetividade:

As emoções são a exteriorização da afetividade [...]. Nelas que assentam os exercícios gregários, que são uma forma primitiva de comunhão e de comunidade. As relações que elas tornam possíveis afinam os seus meios de expressão, e fazem deles instrumentos de sociabilidade cada vez mais especializados.

Corrobora Oliveira (1992, p. 80) salientando que:

O processo pelo qual as crianças vão se apropriando dos objetos culturais ocorre a partir das experiências vividas entre as pessoas à sua volta; essa "passagem do nível interpsicológico [entre as pessoas] para o nível intrapsicológico [no interior do próprio sujeito] envolve, assim, relações interpessoais densas, mediadas simbolicamente, e não trocas mecânicas limitadas a um patamar meramente intelectual".

O processo de ensino-aprendizagem transita tanto pelo cognitivo quanto pelo afetivo.

Como ponto de partida, é necessário que se faça um recorte sobre a idade das crianças nos anos iniciais do ensino fundamental.

A faixa etária de ingresso no ensino fundamental é seis anos de idade, momento em que a criança está vivenciando o nível simbólico. Para Piaget (1975),

a função simbólica consiste na capacidade que a criança adquire de diferenciar significantes e significados. Por meio de suas manifestações, a criança torna-se capaz de representar um significado (objeto, acontecimento) através de um significante diferenciado e apropriado para essa representação (FREITAS, 2010. p. 145). 
Neste estágio, a apropriação do objeto do conhecimento deve estar vinculada ao desejo de querer incorporá-lo. Este desejo, na escola, deve ser estimulado pela afetividade do professor, criando um espaço de acolhimento e bem-estar, que fará o vínculo entre o significado (conhecimento) ao significante (professor).

Momento em que há a importância da intervenção pedagógica, por parte da escola, porém, mais importante ainda, do professor, pela maneira como se coloca, se dispõe e se disponibiliza diante da criança, fará toda a diferença para a escolarização.

Faz-se necessário salientar que demonstrar afetividade não significa não impor limites ou, exigências dentro do novo mundo social que se apresenta à criança, e também, que afetividade vai muito além de abraçar e beijar, ela é uma forma de respeitar a natureza infantil, que é crescer explorando e desenvolvendo suas ideias.

Deste modo, cabe à escola e ao professor, prever condições afetivas que facilitem a aprendizagem, pois se deve considerar o organismo, o corpo, a inteligência e o desejo, como estruturas pertencentes ao indivíduo, e como tal, indissociáveis. A forma como o professor se coloca em relação ao objeto de ensino, o como ele transmite, o quanto ele gosta, o quanto ele se apresenta feliz, criativa e interessada em cada criança, fará com que a aprendizagem tenha um significado positivo, de acolhimento e de sentimento de pertença do aluno quanto ao objeto.

Lorenzoni (2004, p. 20-24) presenta a definição de alguns conceitos,

\begin{abstract}
Afetividade: conjunto de fenômenos psíquicos que se manifestam sob a forma de emoções, sentimentos e paixões, acompanhados, sempre da impressão de dor ou prazer, de satisfação ou insatisfação, agrado ou desagrado, alegria ou tristeza. Afeto: um termo empregado para significar emoção, [...]. Afeto compreende sensações prazerosas, amabilidade, afabilidade, melancolia e antipatia moderada, etc., como também emoções extremas, tais como alegria, hilaridade, medo e ódio. Aprendizagem: uma mudança duradoura no conhecimento, no comportamento ou na compreensão que resulta da experiência. Conhecimento: A apropriação do objeto pelo pensamento, como quer que se conceba essa apropriação: como definição, como percepção clara. Apreensão completa, análise. Ligação reciproca: o nome dado a uma relação positiva entre duas ou mais pessoas em que cada uma gosta da outra. Percepção: Um processo pelo qual analisamos e atribuímos significado às informações sensoriais que recebemos. Vínculo: a formação de uma forte relação (attachment) que geralmente acontece entre as mães e seus bebês.
\end{abstract}

Observando estes conceitos, fica mais fácil a compreensão de que a aprendizagem pressupõe a afetividade. É através das percepções de cada um que ocorre a apropriação de um objeto (conhecimento), estabelecendo vínculos, através da afetividade na qual haverá uma 
ligação recíproca, o que resultará em aprendizagem, e neste processo, o intermediário, aquele que estabelece o vínculo do sujeito com o objeto, realizado também pelo professor, através da afetividade.

Oliveira (1992, p. 80) destaca as experiências vividas como forma de apropriarem-se dos objetos culturais,

passagem do nível interpsicológico [entre as pessoas] para o nível intrapsicológico [no interior do próprio sujeito] envolve, assim, relações interpessoais densas, mediadas simbolicamente, e não trocas mecânicas limitadas a um patamar meramente intelectual.

Deve-se considerar no que diz respeito às questões de afetividade em relação aos alunos, a diversidade dos meios de onde eles vêm. O ser humano é produto do seu meio, e as crianças que não tiveram experiências afetivas positivas, certamente terão maiores dificuldades em estabelecer vínculos.

A fase de desenvolvimento em que as crianças nos anos iniciais do ensino fundamental se encontram, é o período em que o egocentrismo do pensamento préoperacional começa a desaparecer, e a maioria delas já está apta a acomodar-se aos pontos de vista dos outros, o que já é um facilitador ao professor.

\section{Presença da afetividade na lei}

A dimensão afetiva deve estar inserida na aprendizagem escolar e nos seus relacionamentos, pois além de ser algo importantíssimo para que aprendizagem ocorra, também é direito dos alunos. As diretrizes concernentes à formação dos professores (BRASIL, 1999, p. 25), assinalam que uma educação de "qualidade" deve desenvolver, nos aprendizes, diferentes capacidades: "cognitivas, afetivas, físicas, éticas, estéticas, de inserção social e de relação interpessoal".

Já os Parâmetros Curriculares Nacionais (PCN) (BRASIL, 1997, p. 46) apontam a importância de: "relações interpessoais, cognitivas, afetivas e éticas para que o aluno possa dialogar de maneira adequada com a comunidade, e aprenda a respeitar e a ser respeitado, a escutar e ser escutado, a reivindicar seus direitos e a cumprir seus deveres".

O afeto como Princípio Constitucional, também é inerente ao dever familiar e é consequência normativa antes mesmo de ser moral, posto que é abordado intrinsecamente em normas garantistas da Carta Magna. 
Na Carta Magna Brasileira, artigo 227, de onde pode se extrair os deveres que tem a sociedade, o Estado e a família com a formação integral da criança e do adolescente. Apura-se que somente através dos vínculos afetivos é possível cumprir os requisitos da nova ordem jurídica familiar. A educação dada com amor e de forma prazerosa cumpre o princípio da dignidade humana e da paternidade responsável, ofertando qualidade de vida e definindo segundo Caio Mário a convivência familiar como direito fundamental.

No artigo 229, a Constituição Federal, visando a proteção da criança reforça o dever que tem o pai de assistir, criar e educar os filhos menores, posto que estes necessitam da proteção moral, psicológica, intelectual e social de um adulto. A fase infantil é muito importante pelo processo de descobrimento e evolução que tem a criança, portanto o encaminhamento nesta fase é importante para o sucesso de suas qualidades e características futuras.

Os artigos $3^{\circ}$ e $4^{\circ}$ do Estatuto da Criança e do Adolescente, admitindo a condição de desenvolvimento da criança, reforça os Princípios Constitucionais capazes de dar os aportes: moral, físico, psicológico, mental e social, suficientes para a transposição digna desta fase até a vida adulta.

\section{Considerações finais}

O presente trabalho teve a intenção de refletir sobre os conceitos de afetividade e emoção, e a importância destas, em especial nos anos iniciais do ensino fundamental, por serem as responsáveis pelo início de uma escolarização saudável.

Notou-se que a afetividade é um estado psicológico que desempenha um papel importante no desenvolvimento do sujeito e que é responsável pelas suas relações sociais. A afetividade é essencial para a construção das informações cognitivo-afetivas e terão consequências nas relações entre professor-aluno. Observou-se também que emoção e afeto se apresentam de formas distintas, sendo as emoções algo orgânica e visível através dos movimentos das crianças.

Por exemplo, crianças que estão sob efeito das fortes emoções, sofrem uma perda da percepção das coisas ao seu redor, suas atividades cognitivas ficam comprometidas, não raciocinam, não percebem que falam alto, ou que estão com o rosto vermelho, sem contar que podem contaminar os demais colegas. A atenção do professor a todos estes sinais é fundamental, e a pouca clareza na leitura destes atos pode comprometer a relação professor aluno, pois, o engano de interpretação destas atitudes, que são imprevisíveis e acontecem 
quando o indivíduo está mais vulnerável, ficarão marcados e poderão fazer com que o aluno fique ressentido e assim bloqueie as suas emoções, rompendo o vínculo.

Saber interpretar as emoções é um pré-requisito para administrá-las. O professor que se deixa levar pelas crises emotivas em sala de aula tem, além do desgaste mental, um desgaste físico também, causando estresse emocional.

Uma forma adequada de controlar as emoções, que pode ser trabalhada dentro do ambiente escolar, é a dramatização, o desenho ou o relato oral, pois, a ativação do córtex frontal é um mecanismo eficiente contra a emoção exacerbada. Criar um ambiente acolhedor, afetivamente equilibrado, proporciona à criança estabilidade emocional. É preciso ter em mente que a evolução é marcada por conflitos, vencer obstáculos, resolver problemas, fazer escolhas. A instituição escolar também proporciona à criança, e a prepara para estas situações, portanto, é importante permitir que as emoções se manifestem, mas com a intenção de compreender seu funcionamento e corrigi-los.

Vale explicar que eliminar a demonstração das emoções causaria problemas na evolução da criança, por este motivo, a escola deve proporcionar atividades que trabalhem as emoções.

Destarte, conclui-se que a afetividade na relação professor-aluno, é imprescindível já que a aprendizagem ocorre entre seres humanos, e estas podem vir, por exemplo, através de elogios depois de uma atividade feita, que encoraje o discente, que o faça sentir-se confortável, que o torne confiante diante de suas atividades.

A afetividade como expressão de sentimentos contribui no processo ensinoaprendizagem de forma inequívoca, pois sem este estabelecimento vincular, a aprendizagem ficará severamente prejudicada uma vez que o desenvolvimento integral de qualquer ser humano passa por experiências de afeto.

O professor deve ser um mediador de conhecimentos não apenas para instruções formais, mas para despertar os alunos para a curiosidade, ensiná-los a pensar, a ser persistentes, a ter empatia e serem autores, e não somente expectadores da sua aprendizagem.

Para finalizar, trazemos a palavras de Freire (1997), que afirma a importância dos componentes afetivos na construção do conhecimento. Diz que devemos evitar o medo dos nossos sentimentos, emoções, desejos, e o medo de que esses ponham a perder a cientificidade. Diz ainda que, o que sabemos, sabemos com o corpo inteiro, com a mente, com os sentimentos, com a intuição e com as emoções. A afetividade constitui um fator muito importante no processo de desenvolvimento humano, e é na relação com o outro, por meio 
desse outro, que o indivíduo poderá se delimitar como pessoa e manter o processo em permanente construção.

AGRADECIMENTOS: Agência de Fomento: FAPESP - Fundação de amparo a pesquisa do estado de São Paulo.

\section{REFERÊNCIAS}

ALMEIDA, A. R. S. A emoção e o professor: um estudo à luz da teoria de Henri Wallon. Psicologia: Teoria e Pesquisa, v. 13, n. 2, p. 239-249, 1997.

ALMEIDA, A. R. S. As emoções na sala de aula. Campinas, SP: Ed. Papirus, 1999.

COSTA, K. S. da; SOUZA, R. K. M. de. O aspecto sócio-afetivo no processo ensinoaprendizagem na visão de Piaget, Vygotkky e Wallon. Disponível em:

http://www.educacaoonline.pro.br/index.php?option=com_content\&view=article\&id=299:oas pecto-socio-afetivo-no-processo-ensino-aprendizagem-na-visao-de-piagetvygotskyewallon\&catid=4:educacao\&Itemid=15. Acesso em: 19 nov. 2018

DEWEY, J. A Escola e a Sociedade/ A criança e o currículo. Editora Relógio D'água, 2002. Ano copyright, 1902.

DEWEY, J. Democracia e Educação. 3. ed. São Paulo: Nacional, 1959.

FONSECA, V. Neuropsicologia: cérebro, corpo e motricidade. Rev Psique: Ciência Vida, 2016; 123 (dossier: Enigmático Cérebro), p. 37-53.

FONSECA, V. Dificuldades de aprendizagem não verbais. Rev. Inclusão, 2000; v. 1, p. 89112.

FREIRE, P. Pedagogia da Autonomia: Saberes necessários à prática educativa. São Paulo: Paz e Terra, 1996.

GOLEMAN, D. Inteligência emocional: a teoria revolucionária que redefine o que é ser inteligente. Rio de Janeiro: Objetiva, 2012.

GOLEMAN, D. O cérebro e a inteligência emocional: novas perspectivas. Rio de Janeiro: Objetiva, 2012.

LORENZONI, N. V. Vínculo Afetivo e Aprendizagem. Porto Alegre, EST, 2004.

OLIVEIRA, M. K. de. O problema da afetividade em Vygotsky. In: LA TAILLE, Y.; DANTAS, H.; OLIVEIRA, M. K. Piaget, Vygotsky e Wallon: teorias psicogenéticas em discussão. São Paulo: Summus Editorial Ltda, 1992.

PIAGET, J. A epistemologia genética. Trad. Nathanael C. Caixeira. Petrópolis: Vozes, 1971. 
PIAGET, J.; INHELDER, B. A psicologia da criança. 11. ed. Rio de Janeiro: Bertrand Brasil, 1990.

PIAGET, J. Para Onde Vai a Educação? Rio de Janeiro: José Olympo , 9. ed., 1988.

SNYDERS, G. Alunos felizes. São Paulo: Paz e terra, 1993.

TEIXEIRA, A. Pequena introdução à filosofia da educação - escola progressiva ou a transformação da escola. 6. ed. Rio de Janeiro: DP\&A Editora, 2000.

VAN DER VEER, R.; VALSINER, J. Vygostsky: uma síntese. São Paulo: Unimarco/Loyola, 1996.

VYGOTSKY, L. S. Pensamento e Linguagem. São Paulo: Martins Fontes, 1993.

VYGOTSKY, L. S. O desenvolvimento psicológico na infância. São Paulo: Martins Fontes, 1998.

WALLON, H. As origens do caráter na criança. São Paulo: Difusão Europeia, 1971.

WALLON, H. A evolução psicológica da criança. Lisboa, Persona/Martins Fontes, 1968.

WALLON, H. Psicologia. Weber M. J. S.; Brulfert J. N. (org.). São Paulo, Ática, 1986.

WALLON, H. Psicologia e Educação da Infância. Lisboa: Estampa, 1975.

ROURKE B. Nonverbal learning disabilities: the syndrome and the model. New York: Guilford; 1989.

\section{Como referenciar este artigo}

FERREIRA, Gabriella Rossetti; RIBEIRO, Paulo Rennes Marçal. A importância da afetividade na educação. Doxa: Rev. Bras. Psico. e Educ., Araraquara, v. 21, n. 1, p. 88-103, jan./jun. 2019. e-ISSN: 2594-8385. DOI: https://doi.org/10.30715/doxa.v21i1.12003

Submetido em: 01/09/2018

Revisões requeridas: 10/11/2018

Aprovado em: 15/01/2019

Publicado em: 01/02/2019 